\title{
PM-GCD - a combined IR-MW satellite technique for frequent retrieval of heavy precipitation
}

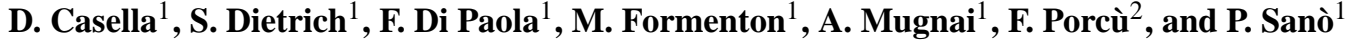 \\ ${ }^{1}$ Istituto di Scienze dell' Atmosfera e del Clima, CNR, Roma, Italy \\ ${ }^{2}$ Dipartimento di Fisica, Università di Ferrara, Ferrara, Italy
}

Correspondence to: D. Casella (daniele.casella@artov.isac.cnr.it)

Received: 15 April 2011 - Revised: 20 October 2011 - Accepted: 31 October 2011 - Published: 31 January 2012

\begin{abstract}
Precipitation retrievals based on measurements from microwave (MW) radiometers onboard low-Earth-orbit (LEO) satellites can reach high level of accuracy - especially regarding convective precipitation. At the present stage though, these observations cannot provide satisfactory coverage of the evolution of intense and rapid precipitating systems. As a result, the obtained precipitation retrievals are often of limited use for many important applications - especially in supporting authorities for flood alerts and weather warnings. To tackle this problem, over the past two decades several techniques have been developed combining accurate MW estimates with frequent infrared (IR) observations from geosynchronous (GEO) satellites, such as the European Meteosat Second Generation (MSG). In this framework, we have developed a new fast and simple precipitation retrieval technique which we call Passive Microwave - Global Convective Diagnostic, (PM-GCD). This method uses MW retrievals in conjunction with the Global Convective Diagnostic (GCD) technique which discriminates deep convective clouds based on the difference between the MSG water vapor $(6.2 \mu \mathrm{m})$ and thermal-IR $(10.8 \mu \mathrm{m})$ channels. Specifically, MSG observations and the GCD technique are used to identify deep convective areas. These areas are then calibrated using MW precipitation estimates based on observations from the Advanced Microwave Sounding Unit (AMSU) radiometers onboard operational NOAA and Eumetsat satellites, and then finally propagated in time with a simple tracking algorithm. In this paper, we describe the PM-GCD technique, analyzing its results for a case study that refers to a flood event that struck the island of Sicily in southern Italy on 12 October 2009.
\end{abstract}

\section{Introduction}

It is well known that precipitation retrievals based on measurements from space-borne microwave (MW) radiometers can reach a high level of accuracy for convective precipitation (Ebert et al., 1996; Smith et al., 1998; Kummerow et al., 2001). However, these observations are taken from low-Earth-orbit (LEO) satellites and therefore do not provide satisfactory coverage of rapidly evolving precipitation systems. To solve this problem, over the past two decades several techniques have been developed that combine accurate $\mathrm{MW}$-based rain rate estimates with frequent infrared (IR) observations from geosynchronous (GEO) satellites (Adler et al., 1993; Xu et al., 1999; Bellerby et al., 2000; Sorooshian et al., 2000; Turk et al., 2000; Huffman et al., 2001; Miller et al., 2001; Kuligowski, 2002; Kidd et al., 2003; Joyce et al., 2004; Turk and Miller, 2005).

In spite of the considerable number of existing MWIR combined techniques, it is very important to develop simple, operator-oriented satellite monitoring tools in order to provide guidance and support to the authorities in raising flood alerts. Evidently, this becomes vital whenever there is a lack of an adequate radar network or in the presence of a complex orography, as in the Mediterranean area - see, for instance, the European Commission RISKMED (http://www.riskmed.net/results.asp) and FLASH (http://flash-eu.tau.ac.il/) projects.

In this framework, we have developed a new fast and simple technique that combines MW rain rate estimates and IR observations to provide precipitation estimates from heavy convective storms at the GEO time and space resolution. The technique can be considered as an evolution of the High Precipitation NAW Areas (HPNA) method (Porcù et al., 1999; Kotroni et al., 2005), which is based on the NegriAdler-Wetzel (NAW) technique (Negri et al., 1984) to define low and high precipitation areas from thermal-IR GEO 
observations. However, while NAW uses pre-assigned rainrate values for the high precipitation areas (defined as the $10 \%$ coldest portion of the cloud top), HPNA uses average values from corresponding MW precipitation retrievals. Then, it employs a simple tracking algorithm to follow the evolution of the high precipitating areas whose average rain rate values are kept constant until a new MW observation becomes available.

The basic innovation of the new technique described in this paper is that it is based on the Global Convective Diagnostic (GCD) approach (Mosher, 2001, 2002) rather than on the NAW method. GCD is a bispectral day and night scheme (based on thermal infrared and water vapor channels) for deep convection operational mapping of geostationary satellite images. Referring to deep-convection observations from the Precipitation Radar (PR) onboard the Tropical Rainfall Measurement Mission (TRMM), Martin et al. (2008) noted that GCD produces more accurate results than any monospectral infrared convective scheme.

Another innovation is related to the computation of the rain rate within each selected area. Contrary to HPNA, PMGCD does not assign an average estimate for the whole area, but it assigns a single value for each GEO pixel, which is computed by means of dynamical relationships between the MW-derived rain rates and the brightness temperature difference between the water vapor and thermal-infrared channels that are updated every time a new MW observation becomes available.

PM-GCD is here described with reference to a floodproducing storm that occurred on 1-2 October 2009 in Sicily in southern Italy - see Dietrich et al. (2011) for a detailed description of this case study. The MW-derived rain rates are based on all available observations from the Advanced Microwave Sounding Unit-A \& -B (AMSU-A, AMSU-B) and Microwave Humidity Sounder (MHS) radiometers onboard NOAA \& MetOp operational LEO satellites. Finally, a preliminary evaluation of the technique has been performed by comparing the evolving PM-GCD rain maps with the corresponding AMSU-based retrievals.

\section{Case study}

Between 30 September and 1 October 2009, a depression centered over Algeria developed over NW Africa, thus driving a warm advection toward the central Mediterranean basin. In this situation, a strong southern flux formed along the Sicily channel and collected a large amount of moisture from the warm sea surface. The interaction with the Eastern Atlas mountains generated gravity waves and low level convergence lines that trigged extensive and strong convection over the sea. This deep convection has been confirmed by the heavy electrical activity present over the central Mediterranen. During 1 October, the cyclone strengthened and moved eastward provoking severe convective rainfall over Sicily.
35 people died because of a large landslide that affected the area around Messina.

The case study considered in this paper covers the time from 1 October 2009, 13:01 UTC till 2 October 2009, 04:14 UTC in the region $30^{\circ} \mathrm{N}-45^{\circ} \mathrm{N}$ latitude $0^{\circ}-30^{\circ} \mathrm{E}$ longitude. During this period, the selected area was observed 7 times by the AMSU radiometers onboard NOAA and MetOp satellites, and was continuously monitored every 15 min by the SEVIRI radiometer on the geostationary MSG satellite. Specifically, MSG observations were taken at minutes 12, 27, 42 and 57 of every hour while MW observations refer to the following dates and times: 1 October 2009 (13:01, 13:05, 14:17, 15:56, and 19:51 UTC); 2 October 2009 (01:24 and 04:12 UTC). Unfortunately, overpass 3 (in italics) observed just a small fraction of the selected area missing the most important storm cells; thus, it has been rejected, reducing the number of available MW observations to 6 in $15 \mathrm{~h}$ and $11 \mathrm{~min}$. We note here that contiguous MW and MSG observations have been considered as simultaneous, the time difference being less than $7.5 \mathrm{~min}$.

\section{The PM-GCD technique}

The Global Convective Diagnostic (GCD) technique was developed by Mosher $(2001,2002)$ in order to delineate deep-convection areas from GEO observations. To this end, GCD computes for each GEO pixel the brightness temperature $\left(T_{\mathrm{B}}\right)$ difference $\left(\Delta T_{\mathrm{B}}\right)$ between the water vapor (WV; $6.2 \mu \mathrm{m}$ ) and the thermal-infrared (IR; $10.8 \mu \mathrm{m}$ ) channels (i.e., $\left.\Delta T_{\mathrm{B}}=T_{\mathrm{B}}^{\mathrm{WV}}-T_{\mathrm{B}}^{\mathrm{IR}}\right)$ and assigns deep convection when that difference is higher than a given threshold (usually, $-1 \mathrm{~K}$ ).

Figure 1 shows the $\Delta T_{\mathrm{B}}$ values for the adopted case study on 2 October 2009, 01:27 UTC together with the corresponding lightning observations and rainfall rates from AMSU. In this paper, the AMSU-based instantaneous rain rates have been obtained by means of the neural network algorithm developed by Surussavadee and Staelin (2008a, b). Lightning data have been provided by the ground-based Lightning Detection Network (LINET) developed at the University of Munich, Germany, which is serviced and continuously operated by Nowcast GmbH (see Betz et al., 2009).

Evidently, $\Delta T_{\mathrm{B}}$ is highly variable and appears to be somewhat related to storm intensity. The regions with higher $\Delta T_{\mathrm{B}}$ values tend to correspond to regions with the highest flash number and the largest rain rates. This latter point is better visualized considering the two $\Delta T_{\mathrm{B}}$ contours $(-5.5 \mathrm{~K}$ and $1 \mathrm{~K}$ ) superimposed on the rain rate map. In particular, the $\Delta T_{\mathrm{B}}=-5.5 \mathrm{~K}$ contour delineates the large precipitation area on the Mediterranean sea southeast of Italy very well, while the $\Delta T_{\mathrm{B}}=1 \mathrm{~K}$ contours inside it tend to correspond with the most active cloud portions. As noted by Thies et al. (2008), the positive $\Delta T_{\mathrm{B}}$ 's are "caused by the presence of water vapor in the lower stratosphere above the cloud which is transported there by deep convection with overshooting tops". 

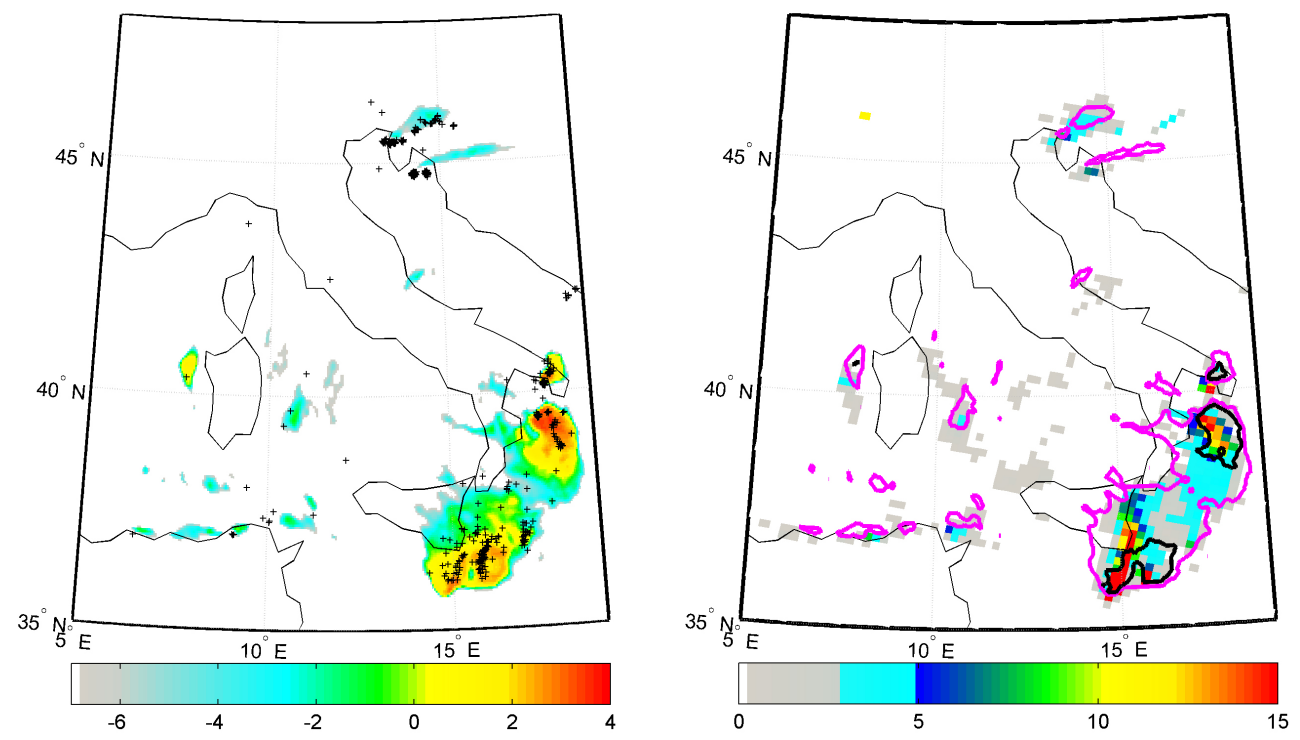

Fig. 1. Left panel: MSG SEVIRI water vapor - thermal infrared brightness temperature difference $\Delta \mathrm{T}_{\mathrm{B}}$ (color scale in $\mathrm{K}$ ) for the selected case study on 2 October 2009, 01:27 UTC. Lightning flashes as observed from the ground-based LINET network over a 10-min period centered at the time of the SEVIRI observation are also shown as black crosses (+). Right panel: Instantaneous rainfall rates (color scale in $\mathrm{mm} \mathrm{h}^{-1}$ ) retrieved from AMSU overpass on 2 October 2009, 01:24 UTC. As a reference, $-5.5 \mathrm{~K}$ (pink line) and $1 \mathrm{~K}\left(\mathrm{black}\right.$ line) $\Delta \mathrm{T}_{\mathrm{B}}$ contours, as derived from the left panel, are also shown.

PM-GCD is an improvement of the High Precipitation NAW Areas (HPNA) method (Porcù et al., 1999; Kotroni et. al., 2005.), which was developed in order to discriminate heavy precipitation areas and assign them mean rainfall values. To this end, HPNA first uses thermal-IR GEO observations to delineate high precipitation areas by means of the coldest $10 \%$ fraction of the cloud-top temperature - as in the Negri Adler Wetzel (NAW) technique (Negri et al., 1984) and then MW observations from LEO satellites to estimate mean rainfall values within such areas. Figure 2 shows the HPNA high precipitation areas for the same case study in Fig. 1. It is evident that HPNA generates several high precipitation areas even in correspondence of low-precipitation or no-precipitation cloud portions, as detected by the MW retrieval algorithm. In contrast, the $\Delta T_{\mathrm{B}}=1 \mathrm{~K}$ contours shown in Fig. 1 do not exhibit any such false alarms of convective cells. Specifically, HPNA high precipitation areas tend to correspond to regions of high MW-retrieved precipitation only in the presence of cumulonimbus clouds in a mature stage, such as the two cells on the Mediterranean sea southeast of Italy. In contrast, by using the difference between two Meteosat channels, the GCD technique performs better in discriminating cumulonimbus from other kinds of clouds and in distinguishing the various parts of a cumulonimbus as convective cells and anvils.

Thus, a test of the sensitivity of GCD to MW-retrieved rain rate (RR) has been performed by considering the $\mathrm{RR}$ distributions in areas limited between couples of $\Delta T_{\mathrm{B}}$ thresholds. The results are shown in Fig. 3 taking into
Table 1. Contingency table for the definition of Probability of Detection (POD), False Alarm Rate (FAR) and Equitable Threat Score (ETS). Success Y is contemporaneous presence of precipitation for the selected pixel both from AMSU-based retrieval and from PMGCD algorithm.

\begin{tabular}{c|ccc}
\hline & \multicolumn{2}{|c}{ MW-precipitation } \\
\hline \multirow{3}{*}{ GCD } & & Y & N \\
& Y & a & c \\
& N & b & d \\
\hline
\end{tabular}

account all AMSU overpasses for the present case study. While for threshold values lower than -0.5 all distributions are very similar to each other showing a strong peak at $\mathrm{RR}=0 \mathrm{~mm} \mathrm{~h}^{-1}$, they move towards higher RR values as the thresholds increase - up to showing an oscillating behavior (with two distinct peaks at about 6 and $20 \mathrm{~mm} \mathrm{~h}^{-1}$ ) for the largest threshold case $\left(3 \mathrm{~K} \leq \Delta T_{\mathrm{B}} \leq 3.5 \mathrm{~K}\right)$. Nevertheless, it is evident that these results cannot be used to find useful relationships between the two quantities since the RR distributions tend to become too flat for the larger threshold values.

However, a stronger correlation between $\Delta T_{\mathrm{B}}$ and RR can be found if we limit our analysis to a single cloud and to a given time - and especially so for deep, convective storms. Thus, the local empirical relation between the two quantities can be used to calibrate $\Delta T_{\mathrm{B}}$ in terms of corresponding RR values. Figures 4 and 5 show two examples of the calibration process we have developed for PM-GCD. Noteworthy, 


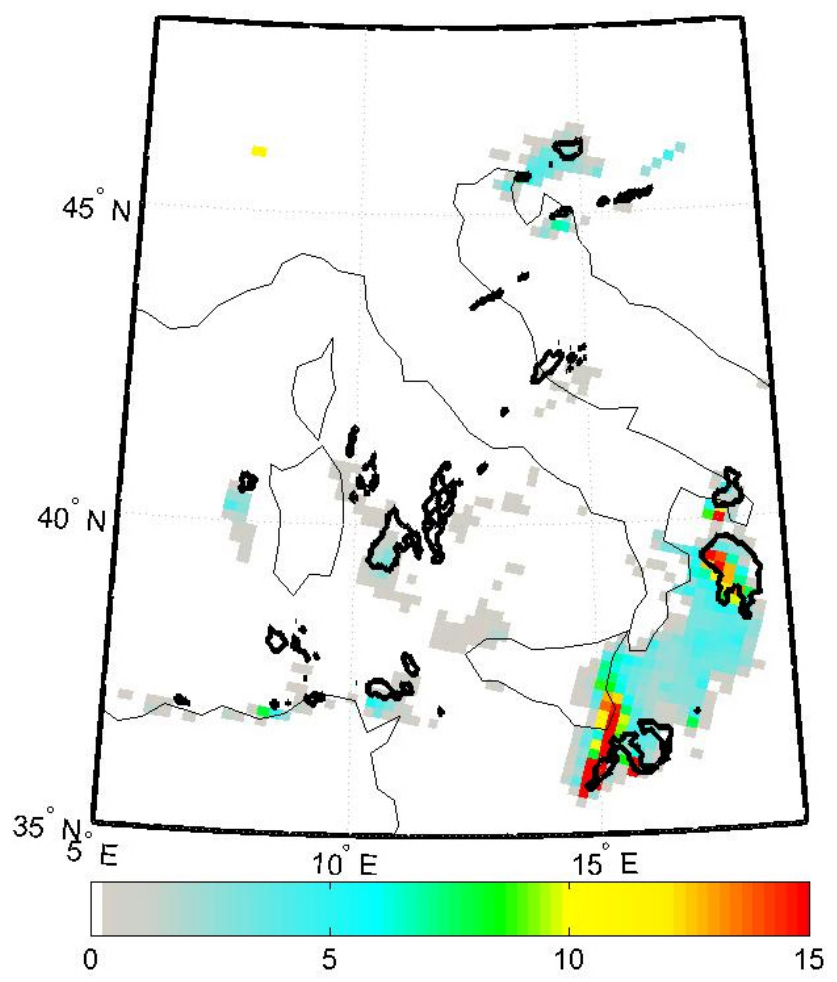

Fig. 2. Instantaneous rainfall rates (color scale in $\mathrm{mm} \mathrm{h}^{-1}$ ) retrieved from an AMSU overpass on 2 October 2009, 01:24 (same as right panel of Fig. 1), and corresponding HPNA high-precipitation areas (black contours).

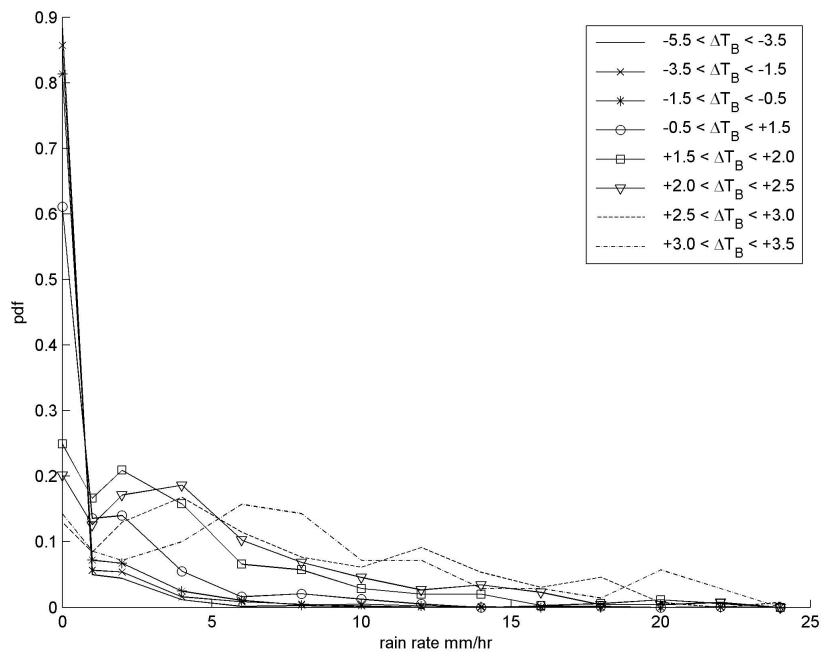

Fig. 3. Probability distribution functions (pdf's) of MW-retrieved rain rates for all AMSU overpasses of the present case study. Results are shown for areas limited by different couples of $\Delta T_{\mathrm{B}}$ thresholds, as indicated in the legend.

PM-GCD performs this calibration every time a MW overpass is available and for each precipitating cloud that is observed - each precipitation area is defined here as the area limited by the $\Delta T_{\mathrm{B}}=-5.5 \mathrm{~K}$ contour, as in Fig. 1 (this value will be discussed in detail later in this section). Then, for each cloud the calibration is maintained for all GEO observations till a new MW overpass is available.

In order to generate the $\Delta T_{\mathrm{B}}-\mathrm{RR}$ relationships for each cloud and each couple of GEO-LEO corresponding observations, we have found it useful to group the $\left(\Delta T_{\mathrm{B}}, \mathrm{RR}\right)$ values that refer to all cloud pixels into $0.5 \mathrm{~K} \Delta T_{\mathrm{B}}$-intervals centered at $0 \mathrm{~K}, \pm 0.5 \mathrm{~K}, \pm 1 \mathrm{~K}, \pm 1.5 \mathrm{~K}, \pm 2 \mathrm{~K}$, and so on, and to the average RR values within such intervals. Incidentally, this helps to take into account the $0.25 \mathrm{~K}$ radiometric accuracy of the thermal-IR and water vapor channels, as well as the variable accuracy of the MW rainfall retrievals. As clearly shown by the two examples of Figs. 4 and 5, we find that these sets of average $\left(\Delta T_{\mathrm{B}}, \mathrm{RR}\right)$ values can be fitted by exponential functions:

$\mathrm{RR}=\alpha \cdot \exp \left(\beta \cdot \Delta \mathrm{T}_{\mathrm{B}}\right)$

where the best-fit coefficients $\alpha$ and $\beta$ can vary considerably from case to case. Note that this function was already used in other algorithms, i.e. in the auto-estimator algorithm (Vicente et al., 1998) it was used to calibrate a single IRchannel brightness temperature to ground radar-based rain rates. However, the PM-GCD technique calculates one couple of $\alpha$ and $\beta$ parameters for each cloud and for each time a new MW observation is available. These two figures also show that the rain intensity pattern within each PM-GCD precipitation area is very similar to that retrieved from the corresponding AMSU observation; in particular, the most convective regions that are characterized by the largest precipitation values in the PM-GCD approach tend to match the AMSUbased high precipitation regions, with the significant exception of the convective cell over south-eastern Sicily in Fig. 5 - as a result, the highest PM-GCD rain intensities within this cell are significantly lower than those retrieved from AMSU.

Then, PM-GCD applies the above calibration/fitting formula to associate rain rates to all pixels of all GEO images of the selected cloud until a new MW observation. In addition, PM-GCD incorporates a simple cloud tracking algorithm in order to follow the evolution of the various precipitating clouds from a GEO observation to the next one. PMGCD produces a rain map for each IR-GEO observation, a map every $15 \mathrm{~min}$ is provided using the MSG. The calculation time is less than $40 \mathrm{~s}$ using a $2.50 \mathrm{GHz}$ Xeon CPU on a $18000000 \mathrm{~km}^{2}$ domain.

We now consider in some detail the problem of defining the precipitating clouds in a MSG observation by means of the GCD approach - i.e., of defining the minimum threshold $\left(\Delta T_{\mathrm{B}, \mathrm{min}}\right)$ contours that best approximate the precipitation areas. To this end, we have compared GCD areas limited by different threshold values with the corresponding MW-retrieved precipitation areas (defined as those areas with $\mathrm{RR}>0 \mathrm{~mm} \mathrm{~h}^{-1}$ ) for all AMSU observations over the Mediterranean region of interest from 1 October 2009, 00:00 UTC till 2 October 2009, 12:00 UTC. Then, we have 

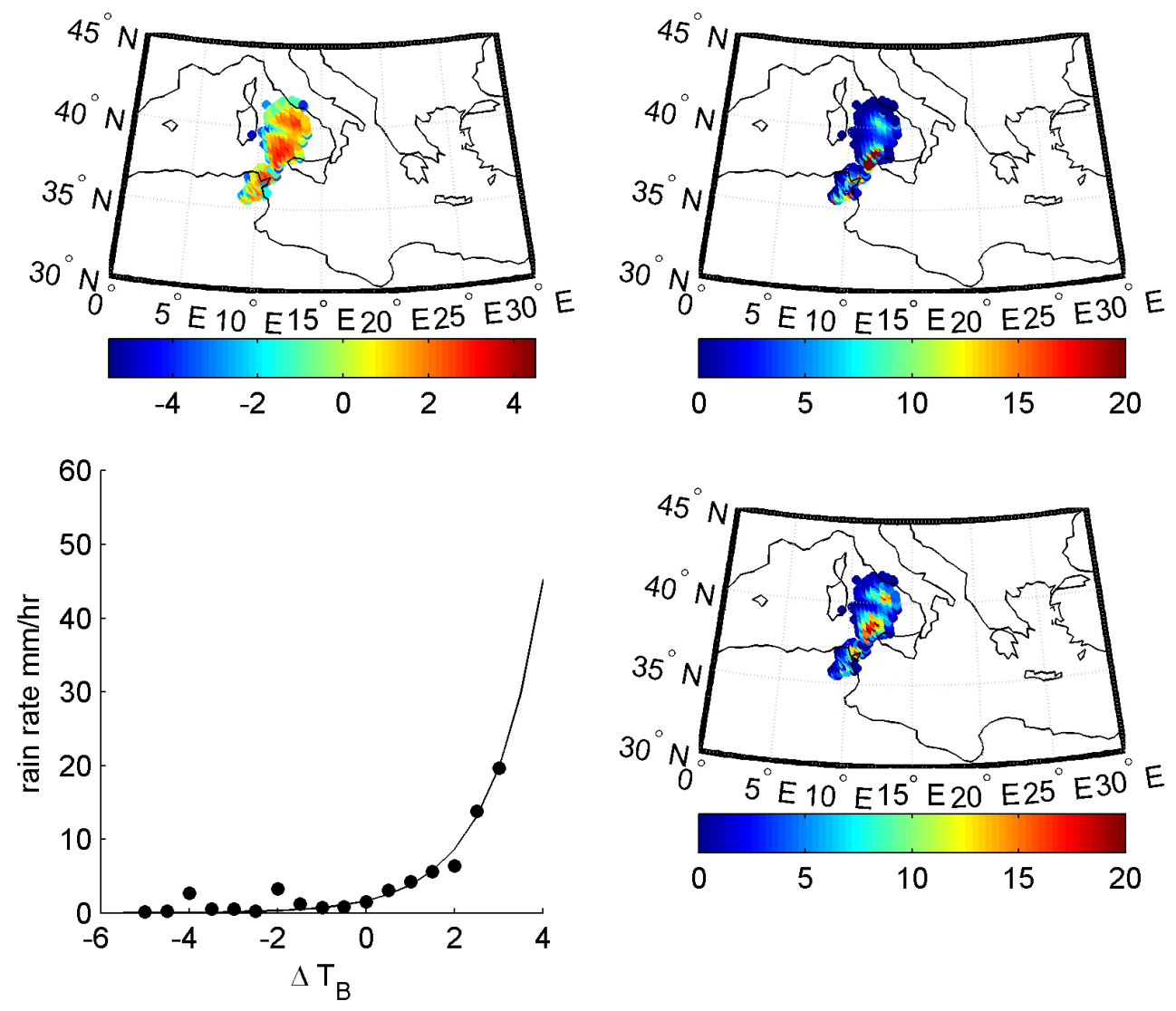

Fig. 4. Illustration of the PM-GCD calibration procedure for the selected case study. Top left panel: $\Delta T_{\mathrm{B}}$ 's (color scale in K) for the main cloud at 12:57 UTC of 1 October 2009. Top right panel: Instantaneous rainfall rates RR (color scale in $\mathrm{mm} \mathrm{h}^{-1}$ ) for the same cloud, retrieved from corresponding AMSU overpass at 13:01 UTC, 1 October 2009. Bottom left panel: Average $\left(\Delta T_{\mathrm{B}}, \mathrm{RR}\right)$ values (dots) within $0.5 \mathrm{~K} \Delta T_{\mathrm{B}}$-intervals centered at $0 \mathrm{~K}, \pm 0.5 \mathrm{~K}, \pm 1 \mathrm{~K}, \pm 1.5 \mathrm{~K}, \pm 2 \mathrm{~K}$, etc., as derived from top panels, and corresponding calibration/fitting exponential function (solid line). Bottom right panel: PM-GCD rain rates (color scale in $\mathrm{mm} \mathrm{h}^{-1}$ ) for the selected cloud, computed by applying the calibration function of the bottom left panel to the $T_{\mathrm{B}}$ 's of the top left panel.

computed the Equitable Threat Score (ETS) as a function of the adopted threshold $\Delta T_{\mathrm{B}}$ :

$\mathrm{ETS}=\frac{a-\text { hits }_{\text {random }}}{a+b+c-\text { hits }_{\text {random }}}$ hits $_{\text {random }}=\frac{(a+b) *(a+c)}{(a+b+c+d)}$

where integers $a, b, c$ and $d$ are incremented by 1 any time there is an occurrence as defined in Table 1. As shown in Fig. 6, the $\Delta T_{\mathrm{B}}$ threshold for low precipitation that maximizes ETS is between $-4.5 \mathrm{~K}$ and $-6.5 \mathrm{~K}$. Since this threshold value influences only the size of the light precipitation area (which increases by decreasing the threshold) without any significant impact on the high precipitation RR values, we assume a minimum threshold $\Delta T_{\mathrm{B}, \min }=-5.5 \mathrm{~K}$.

\section{Results}

We now apply the PM-GCD technique to the main storm that caused the Messina flood over the entire period it was affecting the island of Sicily. During this 15 -h period, the main storm was observed by AMSU six times. The calibration functions for these AMSU overpasses are shown in Fig. 7. Obviously, there is a high variability of the estimated calibration functions - which makes the calibration process an essential step of PM-GCD algorithm. Nevertheless, it is possible to separate the calibration curves into two groups. The first one contains the curves for the middle part of day 1 October 2009, that have relatively high $\beta\left(\sim 1 \mathrm{~K}^{-1}\right)$ and relatively small $\alpha\left(\sim 1 \mathrm{~mm} \mathrm{~h}^{-1}\right)$ parameters. In the second group of curves, covering the night of 1-2 October, $\alpha$ ranges from 2 to $4 \mathrm{~mm} \mathrm{~h}^{-1}$, while $\beta$ is lower than $0.6 \mathrm{~K}^{-1}$. This different behavior suggests that the first part of the event was characterized by more intense convective cells than during the following night.

Figure 8 shows a comparison between rainfall rates computed by the PM-GCD technique and corresponding MW rain estimates for the 5 different AMSU overpasses to which the technique can be applied. Specifically, each PM-GCD rain map refers to the MSG observation which is closest to 

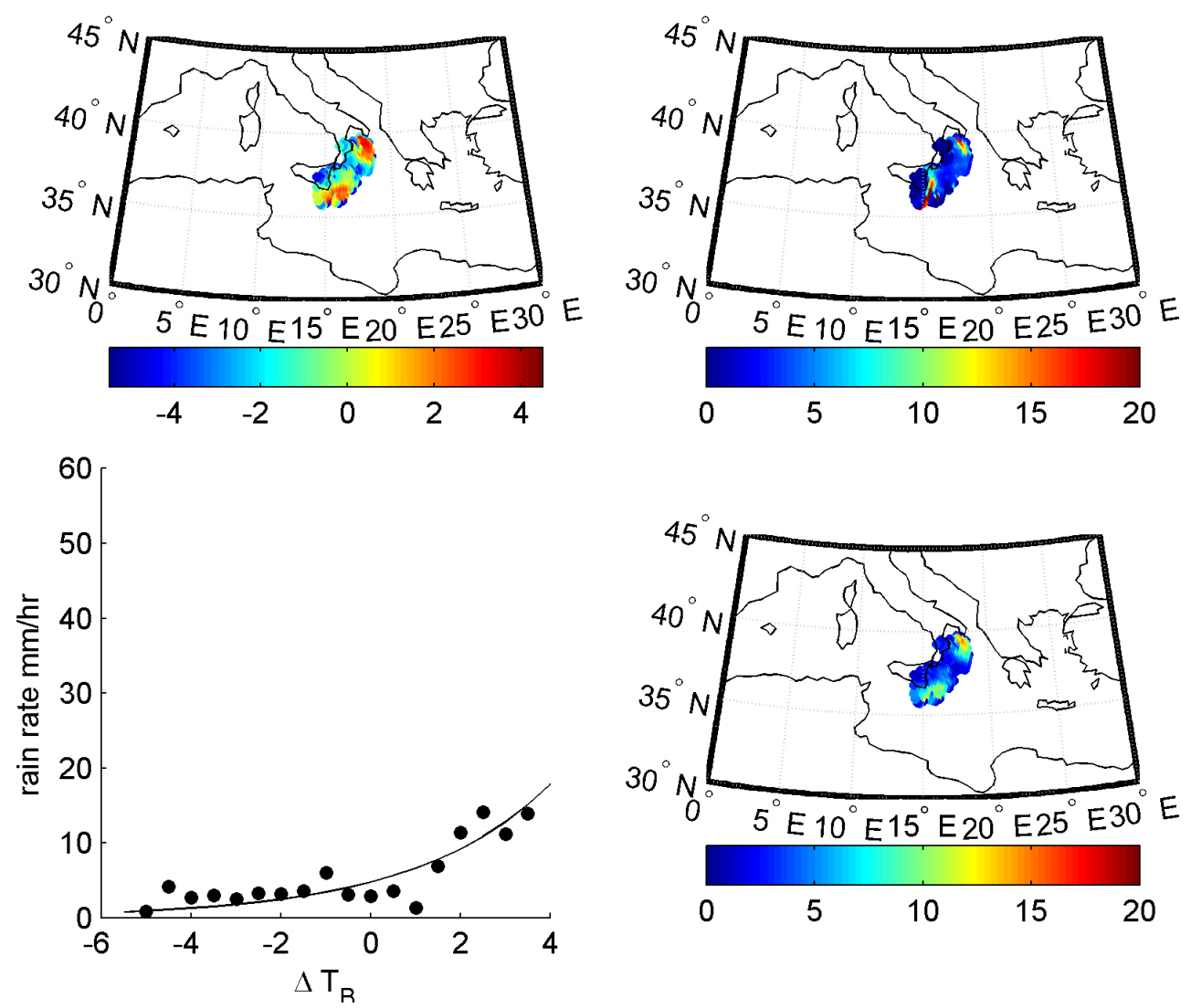

Fig. 5. Same as Fig. 4 but at a different time -2 October 2009, 01:27 UTC for $\Delta T_{\mathrm{B}}$ and 01:24 UTC for RR.

Table 2. Statistical comparison of PM-GCD-based and AMSU-based rain rates for the five rows of Fig. 8. Date and AMSU overpass time are reported in the first two columns. Column Dt refers to the time interval from previous AMSU overpass, while following column $\mathrm{N}$ refers to size of the sample, which is given by the number of MW-radiometer grid pixels considered in the observation. The following four columns show the Probability of Detection (POD), the False Alarm Rate (FAR) and the Equitable Threat Score (ETS) calculated using a $5 \mathrm{~mm} \mathrm{~h}^{-1}$ rain rate threshold and the ETS with a $10 \mathrm{~mm} \mathrm{~h}^{-1}$ threshold. The last four columns show the Correlation $(C)$, Root Mean Squared Error (RMSE), the Mean Absolute Error (MAE) and the Mean Error (ME).

\begin{tabular}{lccccccccccc}
\hline day & hour & $\begin{array}{c}\Delta t \\
(\mathrm{~h}: \mathrm{m})\end{array}$ & $\mathrm{N}$ & $\mathrm{POD}_{5}$ & $\mathrm{FAR}_{5}$ & $\mathrm{ETS}_{5}$ & $\mathrm{ETS}_{10}$ & $\begin{array}{c}C \\
\left(\mathrm{~mm} \mathrm{~h}^{-1}\right)\end{array}$ & $\begin{array}{c}\text { RMSE } \\
\left(\mathrm{mm} \mathrm{h}^{-1}\right)\end{array}$ & $\begin{array}{c}\text { MAE } \\
\left(\mathrm{mm} \mathrm{h}^{-1}\right)\end{array}$ & $\begin{array}{c}\text { ME } \\
\left(\mathrm{mm} \mathrm{h}^{-1}\right)\end{array}$ \\
\hline 1 Oct & $13: 05$ & $0: 04$ & 24390 & 0.71 & 0.36 & 0.50 & 0.42 & 0.72 & 1.29 & 0.14 & 0.02 \\
1 Oct & $15: 56$ & $2: 51$ & 23310 & 0.81 & 0.25 & 0.63 & 0.59 & 0.77 & 1.46 & 0.15 & 0.01 \\
1 Oct & $19: 51$ & $3: 55$ & 24930 & 0.97 & 0.71 & 0.27 & 0.20 & 0.47 & 3.94 & 0.80 & -0.67 \\
2 Oct & $01: 24$ & $5: 33$ & 36630 & 0.29 & 0.16 & 0.27 & 0.00 & 0.57 & 1.53 & 0.17 & 0.14 \\
2 Oct. & $04: 12$ & $2: 48$ & 35100 & 0.77 & 0.50 & 0.42 & 0.46 & 0.59 & 2.02 & 0.26 & 0.01 \\
\hline
\end{tabular}

the corresponding AMSU overpass and is based on the calibration function that is computed for the previous AMSU overpass. Thus, these results may be considered as a first step of the algorithm's validation, where the AMSU-based rainfall rates are taken as the "truth". In order to help the analysis, we report in Table 2 several statistical indexes for the five PM-GCD results of Fig. 8. In particular, the time interval from the previous calibration is reported as $\Delta t$, together with the statistical scores: Probability Of Detection (POD),
False Alarm Rate (FAR), and ETS considering a "success" (see Table 1) rain rates higher than $5 \mathrm{~mm} \mathrm{~h}^{-1}$ or $10 \mathrm{~mm} \mathrm{~h}^{-1}$; in the discussion of the results these threshold values have been used to define conventionally "convective precipitation" or "heavy precipitation" respectively. Together with these statistical scores Table 2 shows the Correlation $(C)$, the Root Mean Square Error (RMSE), the Mean Absolute Error (MAE), and the Mean Error (ME). 


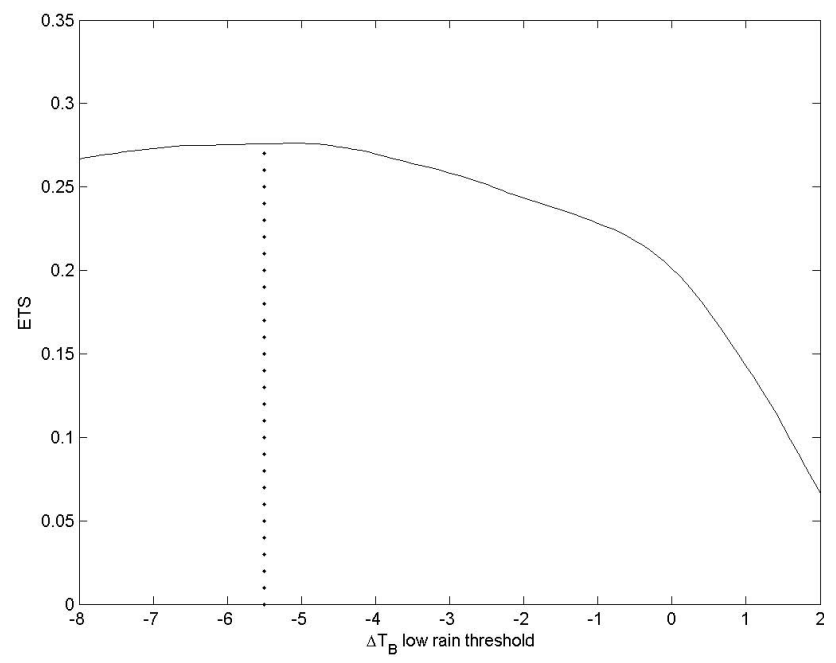

Fig. 6. Equitable Threat Score (ETS) as a function of the $\Delta T_{\mathrm{B}}$ threshold $(\mathrm{K})$ utilized for delineating the precipitating areas $(\mathrm{RR}>0)$ for all AMSU observations of the case study.

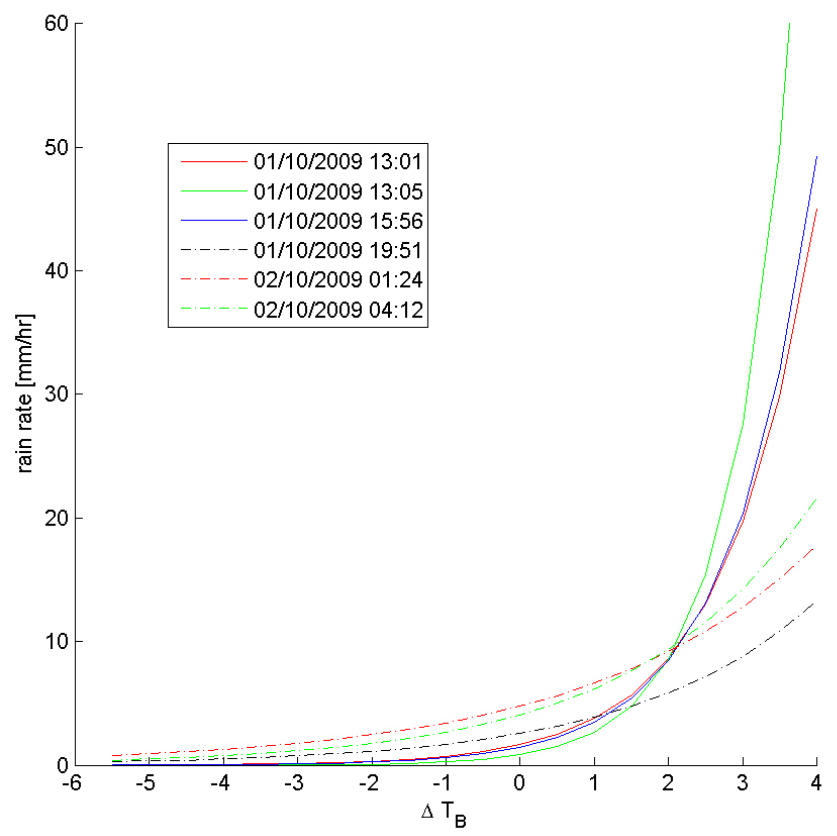

Fig. 7. Calibration functions for the main storm of previous Figs. 4 and 5, corresponding to the 6 different AMSU overpasses indicated in the legend.

Even though small clouds observed as lightly precipitating from the MW estimates are not well detected by PM-GCD, the algorithm shows a generally good detection capability for intense convective clouds - which are the objective of the technique. No significant false alarms in convective precipitation are found, with the only exception of the 19:57 UTC observation $\left(0.71\right.$ FAR $\left._{5}\right)$ over the North African coast. In this case the problem is due to the fact that this small convective cell is first observed by AMSU at this time, and therefore there is not an appropriate calibration function - the algorithm uses a mean calibration function, which evidently produces unreliable rain estimates.

Both Fig. 8 and Table 2 show that the PM-GCD results are in reasonable agreement with the MW-based rain rates whenever the time difference between the considered and previous AMSU overpasses is sufficiently small. Obviously, a good agreement is reached by the PM-GCD for the MSG observation on 1 October 2009, 13:12 UTC because of the very short time difference between the two AMSU overpasses (only $4 \mathrm{~min}$ ) and between the two MSG observations (15 min) that are involved - at 12:57 UTC for generating the calibration curve and at 13:12 UTC for computing the PM-GCD rain maps. Evidently, this is due to the fact that during such short time period the structure of the storm does not change significantly - as indicated by the similarity between the two calibration curves for AMSU overpasses at 13:01 and 13:05 (see previous Fig. 7).

Even the PM-GCD results for the MSG observation at 15:57 UTC are reasonably good in spite of a time difference of almost $3 \mathrm{~h}$ between the two AMSU overpasses of interest - at 13:05 UTC for generating the calibration curve and at 15:56 UTC for generating the reference AMSU-based rain maps. Here, the most striking differences are given by the dimensions of the main storm and of the convective cell over the northwestern corner of Sicily, that are somewhat larger for PM-GCD as compared to the AMSU results. We also note that while the storm had significantly evolved during this 3-h span, the two corresponding calibration curves of Fig. 7 are rather similar. While the reason for this similarity is not evident, this result helps to explain the overall agreement between the PM-GCD and AMSU-based rain rates.

In contrast, PM-GCD produces inadequate results for the two MSG observations on 1 October 2009, 19:57 UTC and on 2 October 2009, 01:27 UTC. At 19:57 UTC, there is a too intense and large convective cell over Sicily in addition to the one over the North African coast that has been mentioned before. Vice versa, the PM-GCD rain fields at 01:27 are too weak compared to the corresponding AMSU observation. We note here that the time difference between the two AMSU overpasses that are involved is almost $4 \mathrm{~h}$ in the first case and $51 / 2 \mathrm{~h}$ in the second case, during which time periods the storm has largely changed - possibly, because of orographic effects over Sicily. We also note that in each case, the calibration curves for the two AMSU overpasses are quite different. In particular, in the first case they belong to the two distinct groups that have been identified when discussing Fig. 7. The indexes of Table 2 are helpful to quantify the bad performances of PM-GCD in these two cases, in particular the ME shows an evident overestimation at 19:57 UTC $\left(\mathrm{ME}=-0.67 \mathrm{~mm} \mathrm{~h}^{-1}\right)$ and an underestimation at 01:27 UTC $\left(\mathrm{ME}=0.14 \mathrm{~mm} \mathrm{~h}^{-1}\right)$ and the poor $\mathrm{ETS}_{5}$ and ETS $_{10}$ scores in both cases quantifies the misallocation of both the convective and heavy precipitating cores. 

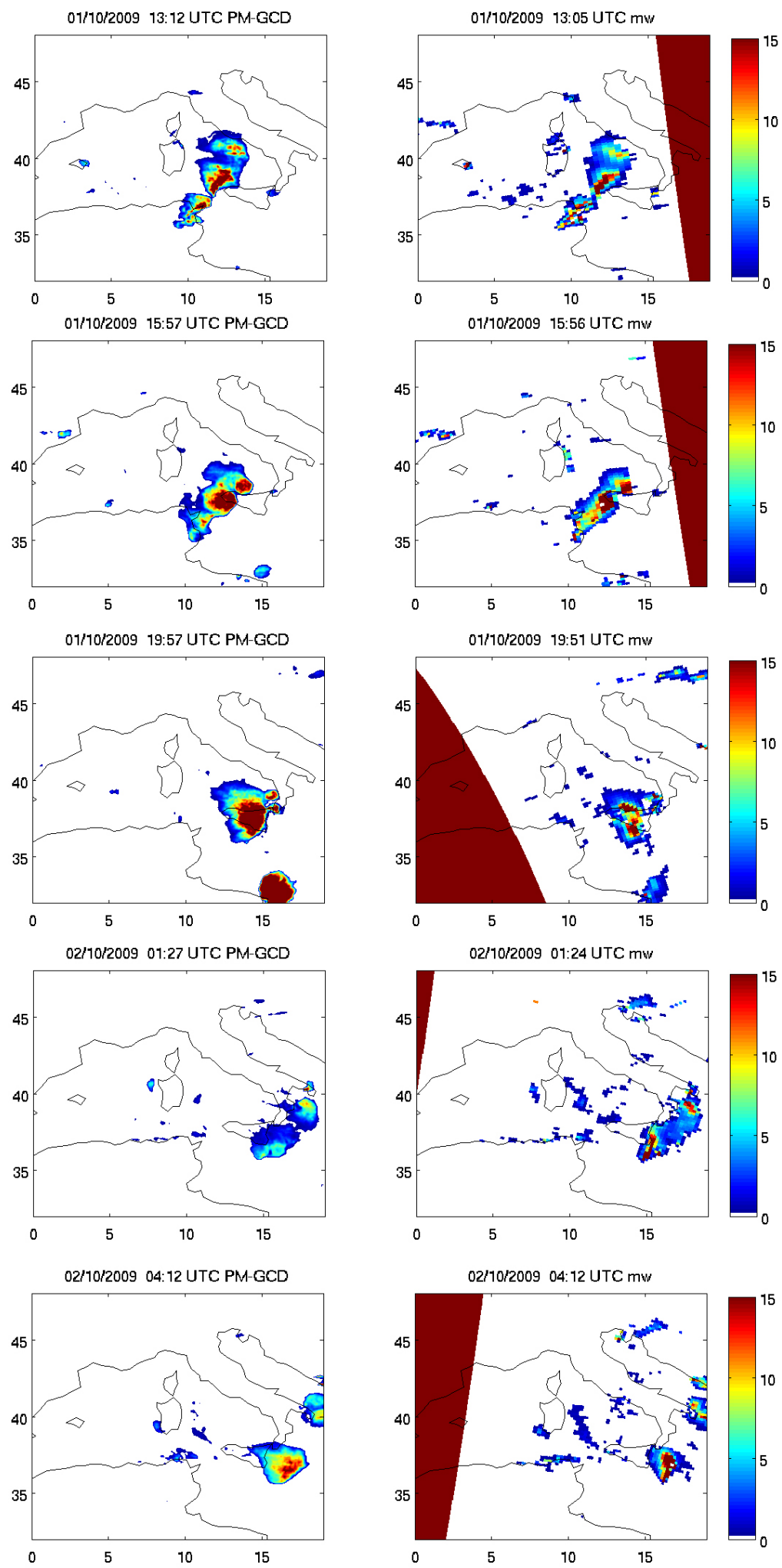

Fig. 8. Comparison of corresponding PM-GCD (left column) and AMSU-based (right column) rainfall rates (color scale in mm $\mathrm{h}^{-1}$ ) for the selected case study. Each PM-GCD panel refers to the MSG observation which is closest to the corresponding AMSU overpass and is based on the calibration function that is computed for the previous AMSU overpass - i.e., from top to bottom: on 2 October 2009 at 13:01, 15:56, 19:51 UTC and on 2 October 2009 at 01:24 UTC. 
Finally, the PM-GCD results for MSG observation on 2 October 2009, 04:12 UTC look better than the previous two cases, but the convective rain cell southeast of Sicily is clearly misplaced - which produces a large $\mathrm{FAR}_{5}(0.50)$. Apart from $\mathrm{FAR}_{5}$, the remaining indexes are comparable to the first two of the case study, especially $\mathrm{ETS}_{5}, \mathrm{ETS}_{10}$ and ME. This result is somehow expected if we consider that the time difference between the two AMSU overpasses of interest is less than $3 \mathrm{~h}$ and that the corresponding calibration curves are almost identical.

In summary, the PM-GCD precipitation estimates from convective clouds strictly depend on the time distance from the last MW calibration, as well as on the nature, speed and stage of evolution of the storm under consideration. While its performance may become unsatisfactory after $2-3 \mathrm{~h}$ from such calibration and while the detailed rain fields may even show significant differences with respect to the "truth", the technique may be very useful for quantitatively monitoring convective $\left(>5 \mathrm{~mm} \mathrm{~h}^{-1}\right)$ and heavy $\left(>10 \mathrm{~mm} \mathrm{~h}^{-1}\right)$ precipitating storms within an operational framework. Therefore, we plan to analyze more case studies under different meteorological and environmental conditions in order to attain a definite assessment of PM-GCD performance.

\section{Conclusions and future work}

PM-GCD is a fast and simple IR-based, MW-calibrated scheme focusing on estimation of convective and heavy precipitation. Due to the possibility of using it every $15 \mathrm{~min}$ during day and night, it can become useful for nowcasting experts and flood alarm managers.

Considering an observation of a typical cumulonimbus, the thermal IR radiance shows very small variations while the GCD value tends to decrease from the core convective cell to the anvil region. Another reason to use GCD instead of single IR-channel techniques is that GCD highly reduces the number of false alarms that was one of the main sources of error of the HPNA technique (both in low and high precipitating areas). Incidentally, even combined blending IRMW algorithms could take advantage of the GCD bispectral technique since they have shown a worse performance than global forecast models at mid-latitudes (Ebert et al., 2007). Another important innovation of PM-GCD is that it does not take into account the $10 \%$ coldest portion of the cloud to define high precipitating areas. It has been noticed that this relation is valid just for a mature cumulonimbus (that is not the most common observed cloud) and results in a false alarm for any other cloud category.

Many of the limits of the PM-GCD technique can be related to the characteristics of present instruments onboard operational satellites. Any satellite-borne IR radiometer senses a signal that is related to the upper cloud levels and is not strictly related to precipitation. Thus, MW calibration becomes essential; however, the number of operational MW radiometers on polar satellites allows only a sporadic calibration process.

In this paper, no radar measurements were available and thus a preliminary validation has been performed by using the AMSU-based rain rates as the "truth". We also note that this is a necessary step to separate the effects strictly related to the algorithm from those that are due to the limited accuracy of the MW retrievals. Nevertheless, we plan to perform an extensive validation of PM-GCD results by means of ground-based and space-borne radars, such as the TRMM $\mathrm{PR}$ and rain gauge networks. We also plan to analyze several case studies under different meteorological and environmental conditions in order to attain a final assessment of the performance of our technique. Then, we plan to integrate it into a nowcasting algorithm in order to make it more useful to the user community. Finally, a potential upgrade of this technique, which is presently under study, consists in combining PM-GCD with the lightning-based technique developed by Dietrich et al. (2011) so as to take advantage of the strengths of the two techniques and reduce their weaknesses.

Acknowledgements. The authors want to thank the anonymous reviewers of this paper for their valuable comments and suggestions. This research has been supported by the European Commission Sixth Framework Programme through the project "Observation, Analysis and Modeling of Lightning Activity in Thunderstorms, for use in Short Term Forecasting of Flash Floods" (FLASH), by the European Community Initiative INTERREG III-B ARCHIMED through the project "Weather Risk Reduction in the Central and Eastern Mediterranean" (RISKMED), by the Italian FISR-MIUR program "Sustainable Development and Climate Changes" through the project "Aerosol Effects on Clouds and Climate" (AEROCLOUDS), and by the Italian Civil Protection Agency. We express special thanks to Alessandro Mattia for his support and help.

Edited by: K. Lagouvardos

Reviewed by: three anonymous referees

\section{References}

Adler, R. F., Keehn, P. R., and Hakkarinen, I. M.: Estimation of monthly rainfall over Japan and surrounding waters from a combination of low-orbit microwave and geosynchronous IR data, J. Appl. Meteor., 32, 335-356, 1993.

Bellerby, T. M., Todd, T., Kniveton, D., and Kidd, C.: Rainfall estimation from a combination of TRMM precipitation radar and GOES multispecral satellite imagery through the use of an artificial neural network, J. Appl. Meteor., 39, 2115-2128, 2000.

Betz, H.-D., Schmidt, K., and Oettinger, W. P.: LINET - An international VLF/LF lightning detection network in Europe, in: Lightning: Principles, Instruments and Applications, edited by: Betz, H.-D., Schumann, U., and Laroche, P., Springer, 115-140, 2009.

Dietrich, S., Casella, D., Di Paola, F., Formenton, M., Mugnai, A., and Sanò, P.: Lightning-based propagation of convective rain fields, Nat. Hazards Earth Syst. Sci., 11, 1571-1581, doi:10.5194/nhess-11-1571-2011, 2011. 
Ebert, E. E., Manton, M. J., Arkin, P. A., Allam, R. J., Holpin, G. E., and Gruber, A. J.: results from the GPCP Algorithm Intercomparison Programme, B. Am. Meteor. Soc., 77, 2875-2887, 1996.

Ebert, E. E., Janowiak, J. E., and Kidd, C.: Comparison of nearreal-time precipitation estimates from satellite observations and numerical models, B. Am. Meteor. Soc., 88, 47-64, 2007.

Huffman, G. J., Adler, R. F., Morrisey, M. M., Bolvin, D. T., Curtin, S., Joyce, R., McGavock, B., and Susskind, J.: Global precipitation at one-degree daily resolution from multisatellite observations, J. Hydrometeor., 2, 36-50, 2001.

Joyce, R. J., Janowiak, J. E., Arkin, P. A., and Xie, P.: CMORPH: A method that produces global precipitation estimates from passive microwave and infrared data at high spatial and temporal resolution, J. Hydrometeor., 5, 487-503, 2004.

Kidd, C. K., Kniveton, D. R., Todd, M. C., and Bellerby, T. J.: Satellite rainfall estimation using combined passive microwave and infrared algorithms, J. Hydrometeor., 4, 1088-1104, 2003.

Kotroni, V., Lagouvardos, K., Defer, E., Dietrich, S., Porcù, F., Medaglia, C. M., Demirtas, M.: The Antalya 5 December 2002 Storm: Observations and Model Analysis, J. Appl. Meteor. Climatol., 45, 576-590, 2005.

Kuligowski, R. J.: A self-calibrating real-time GOES rainfall algorithm for short-term rainfall estimates, J. Hydrometeor., 3, 112 130, 2002.

Kummerov, C., Hong, Y., Holson, W. S., Yang, S., Adler, R. F., McCollum, J., Ferraro, R., Petty, G., Schin, D.-B., and Wilheit, T. T.: The evolution of the Goddard profiling algorithm (GPROF) for rainfall estimation from passive microwave sensors, J. J. Appl. Meteor., 40, 1801-1820, 2001.

Martin, D. W., Kohrs, R. A., Mosher, F. R., Medaglia, C. M., and Adamo, C.: Over-Ocean Validation of the Global Convective Diagnostic, J. Appl. Meteor. Climatol., 47, 525-543, 2008.

Miller, S. W., Arkin, P. A., and Joyce, R.: A combined microwave/infrared rain rate algorithm, Int. J. Remote. Sens., 22, 3285-3307, 2001.

Mosher, F. R.: A satellite diagnostic of global convention, Preprints, 11th Conf on Satellite Meteorology, Madison, WI, Am. Meteor. Soc., 416-419, 2001.

Mosher, F. R.: Detection of deep convection around the globe, Preprints, 10th Conf. on Aviation, Range and aerospace Meteorology, Portland, OR, Amer. Meteor. Soc., 289-292, 2002.
Negri, A. J., Adler, R. F., and Wetzel, P. J.: Rain estimation from satellite: An examination of the Griffith-Woodley technique, J. Climate Appl. Meteor., 23, 102-116, 1984.

Porcù, F., Dietrich, S., Mugnai, A., Natali, S., Prodi, F., Conway, P.: Satellite multi-frequency observations of severe convective systems in the Mediterranean, Phys. Chem. Earth B, 24, 643648, 1999.

Smith, E. ALamm., J. E., Adler, R. F., Alishouse, J., and Aonashi, K.: Results of the WetNet PIP-2 project, J. Atmos. Sci., 55, 1483-1536, 1998.

Sorooshian, S., Hsu, K.-L., Gao, X., Gupta, H. V., Imam, B., and Braithwaite, D.: Evaluation of PERSIANN system satellitebased estimates of tropical rainfall, B. Am. Meteor. Soc., 81, 2035-2046, 2000.

Surussavadee, C. and Staelin, D. H.: Global millimeter-wave precipitation retrievals trained with a cloud-resolving numerical weather prediction model, Part I: Retrieval design, IEEE T. Geosci. Remote Sens., 46, 99-108, 2008a.

Surussavadee, C. and Staelin, D. H.: Global millimeter-wave precipitation retrievals trained with a cloud-resolving numerical weather prediction model, Part II: Performance evaluation, IEEE T. Geosci. Remote Sens., 46, 109-118, 2008b.

Thies, B., Nauss, T., and Bendix, J.: First results on a processoriented rain area classification technique using Meteosat Second Generation SEVIRI night-time data, Adv. Geosci., 16, 63-72, 2008 , http://www.adv-geosci.net/16/63/2008/.

Turk, F. J. and Miller, S. D.: Toward improving estimates of remotely-sensed precipitation with MODIS/ AMSR-E blended data techniques, IEEE T. Geosci. Remote Sens., 43, 1059-1069, 2005.

Turk, F. J., Rohaly, G. D., Hawkins, J., Smith, E. A., Marzano, F. S., Mugnai, A., and Levizzani, V.: Meteorological applications of precipitation estimation from combined SSM/I, in: TRMM and infrared geostationary satellite data, Microwave Radiometry and Remote Sensing of the Earth's Surface and Atmosphere, edited by: Pampaloni, P. and Paloscia, S., VSP Press, 353-363, 2000.

Vicente, G., Scofield, R. A., and Mensel, W. P.: The operational GOES infrared rainfall estimation technique, B. Am. Meteor. Soc., 79, 1883-1898, 1998.

Xu, L., Gao, X., Sorooshian, S., Arkin, P. A., and Imam, B.: A microwave infrared threshold technique to improve the GOES precipitation index, J. Appl. Meteor., 38, 569-579, 1999. 